\title{
DESENVOLVIMENTO RURAL SUSTENTÁVEL E A TECNOLOGIA FOTOVOLTAICA NA REGIÃO ADMINISTRATIVA DE UMUARAMA - PR
}

\section{SUSTAINABLE RURAL DEVELOPMENT AND PHOTOVOLTAIC TECHNOLOGY IN THE ADMINISTRATIVE REGION OF UMUARAMA - PR}

\author{
Igor Talarico da Silva Micheletti ${ }^{1}$; Diane Belusso ${ }^{2}$
}

1. Mestrando no Programa de Pós-graduação em Sustentabilidade, IFPR. E-mail: igor_talarico@ hotmail.com. ORCID: https://orcid.org/0000-0003-2665-6393

2. Doutora em Geografia, UNESP. Professora no Programa de Pós-graduação em Sustentabilidade, IFPR. E-mail: diane.belusso@ifpr.edu.br. ORCID: https://orcid.org/0000-0002-8401-1975.

\section{RESUMO}

A energia solar fotovoltaica tem se mostrado como uma eficiente tecnologia energética renovável, aliada no fomento ao desenvolvimento sustentável. As considerações propostas nesse artigo objetivam analisar os aspectos e conceitos de sustentabilidade ao longo do tempo. Especificamente, visa abranger a tecnologia fotovoltaica como parte do desenvolvimento rural sustentável na Região Administrativa de Umuarama do estado do Paraná. Foi realizada uma revisão bibliográfica com abordagem qualitativa de viés voltado nas teorias de sustentabilidade e desenvolvimento sustentável. Buscou-se compreender os impactos da aplicação de tecnologia na promoção do desenvolvimento rural sustentável, destacando a influência das políticas públicas e da extrafiscalidade no contexto regional. Os resultados apresentados neste trabalho mostram que a aplicação da tecnologia fotovoltaica no setor rural é um fenômeno mundial que está ascendendo na região estudada e no estado do Paraná.

Palavras-Chave: Sustentabilidade; avanços tecnológicos; políticas públicas; geração distribuída; energias renováveis.

\begin{abstract}
Photovoltaic solar energy has proven to be an efficient renewable energy technology, allied to promoting sustainable development. The considerations proposed in this article aim to analyze the aspects and concepts of sustainability over time. Specifically, it aims to encompass photovoltaic technology as part of sustainable rural development in the Administrative Region of Umuarama in the state of Paraná. A literature review was carried out with a qualitative and quantitative approach with a bias towards the theories of sustainability and sustainable development. We sought to understand the impacts of the application of technology in promoting sustainable rural development, highlighting the influence of public policies and extrafiscality in the regional context. The results presented in this work show that the application of photovoltaic technology in the rural sector is a worldwide phenomenon that is rising in the studied region and in the state of Paraná.
\end{abstract}

KEY WoRDS: Sustainability; technological advancements; public policy; distributed generation; renewable energy. 


\section{INTRODUÇÃO}

A definição mais aceita para desenvolvimento sustentável surgiu na Comissão Mundial sobre o Meio Ambiente e Desenvolvimento, no qual sugere que o desenvolvimento sustentável é capaz de suprir as necessidades da geração atual, sem comprometer a capacidade de atender as necessidades das futuras gerações. É o desenvolvimento que não esgota os recursos para o futuro, aliando assim o desenvolvimento econômico e a conservação ambiental (NAVARRO, 1995).

Ainda sobre o tema Navarro (1995) diz que almejar o desenvolvimento sustentável depende de planejamento e do reconhecimento de que os recursos naturais são finitos. O desenvolvimento sustentável deve ser aplicado de forma a priorizar a qualidade em vez de quantidade, buscando a redução do uso de matérias-primas e produtos otimizando a produção e repensando o consumo.

Esse equilíbrio de produção e consumo reflete muito no modelo atual de desenvolvimento rural e agrícola do Brasil, que tem passado por uma transição, na qual tem como principal objetivo equilibrar a produção em relação a proteção ambiental. Entretanto essa transição para o desenvolvimento rural sustentável depende do equilíbrio entre as políticas de proteção ambiental e os anseios da população rural, buscando equilibrar os pilares ambiental, econômico e social (CAPORAL; COSTABEBER, 2000).

Desde a promulgação da Constituição Federal de 1988, a agropecuária nacional sofreu muitas transformações, abandonando os atrasos oligárquicos e tentando acompanhar a modernidade capitalista, sob o mando da tecnologia, que trouxe um novo contexto ao meio rural. Esse processo de integração da tecnologia teve boa aceitação nacional, entretanto não participaram todos os agricultores e trabalhadores rurais. Esse processo possibilitou a conexão da produção rural com a indústria e os serviços, gerando complexas teias produtivas chamadas de agronegócio (SILVA, 1997).

Dentre a aplicação de tecnologia para fomentar o desenvolvimento rural sustentável, a aplicação de sistemas de energia solar fotovoltaica está se destacando. A energia solar é uma eficiente alternativa de matriz energética renovável facilmente adaptável às necessidades do campo. Isso se deve ao fato de os equipamentos modulares permitirem a instalação em praticamente qualquer lugar, tornando-se uma poderosa ferramenta de produção e autonomia mesmo em áreas muito isoladas. $\mathrm{Na}$ área rural a energia solar é uma tecnologia viável e eficiente para auxiliar na eletrificação rural e no fomento ao desenvolvimento sustentável (NUNES, 2007). 


\section{GESTÃO \& SUSTENTABILIDADE AMBIENTAL}

\section{১unisul sim}

No Brasil tem-se buscado uma diversificação da matriz elétrica nacional, se reduzindo os custos e trazendo mais segurança e estabilidade à matriz. A implantação de tecnologias que aproveitem a luz do sol, principalmente no meio rural, tem-se mostrado eficaz, levando em consideração a viabilidade técnica apresentada em quase todo o território nacional (KEMERICH et al., 2016).

O estado do Paraná possui um grande potencial para aplicação de outras fontes como a solar fotovoltaica (TIEPOLO et al., 2014). Deste modo, o número de unidades consumidoras utilizando sistemas fotovoltaicos vem crescendo, entretanto o avanço na área rural ainda é tímido em relação à área urbana (ANEEL, 2021).

A pesquisa teve como objetivo contextualizar o início e o crescimento da aplicação de geradores solares fotovoltaicos em estabelecimentos rurais no Brasil e no Paraná, dando enfoque a utilização da tecnologia na Região Administrativa de Umuarama - PR, vista na Figura 1, analisando sua importância para a sustentabilidade com base no advento das Resoluções Normativas da ANEEL.

Figura 1. Região Administrativa de Umuarama - PR.

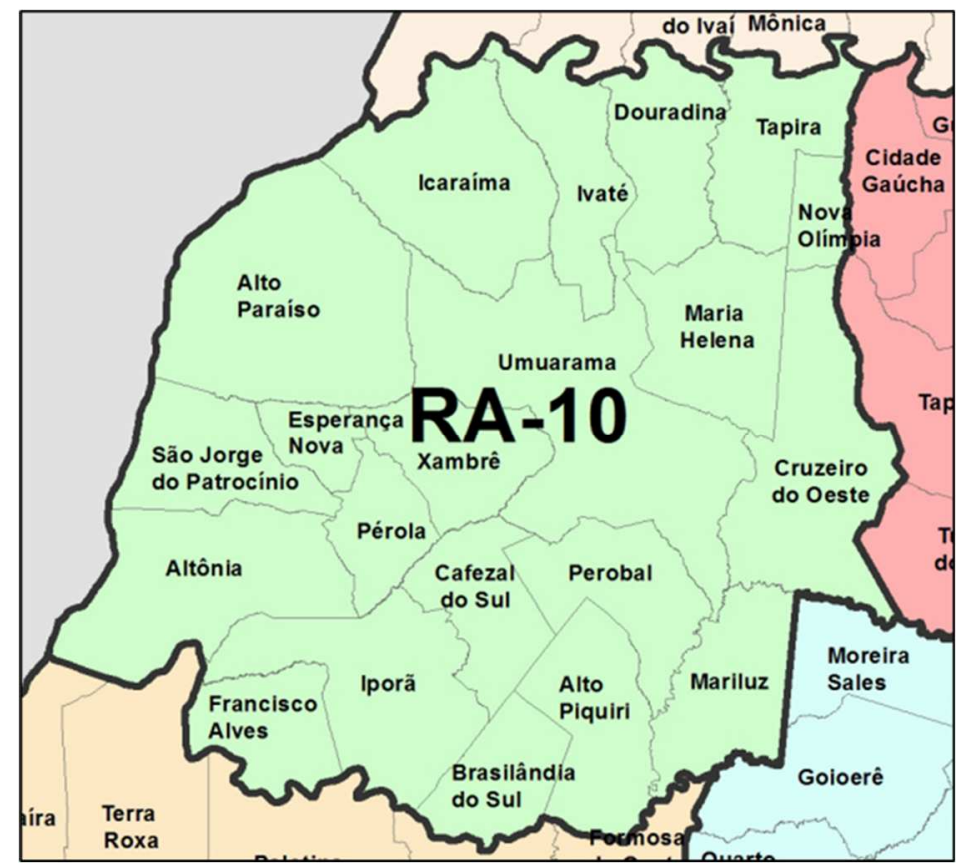

Fonte: IPARDES (2015).

O presente trabalho caracterizou-se como uma pesquisa exploratória de abordagem qualitativa, utilizando-se do método dialético a partir de pesquisas bibliográficas, tendo como principais referenciais bibliográficos autores como Tiepolo et al. (2014); Tolmasquim (2016), Sachs (2009), Boff (2016), Sen (2000) e Poulain (2013). 


\section{CONCEPÇÕES DE DESENVOLVIMENTO SUSTENTÁVEL}

Sabe-se que o termo "desenvolvimento" possui vários significados e pode ser entendido como um processo em evolução, que visa trazer uma conotação positiva às ações fomentadas pela humanidade. Já o termo sustentabilidade traz um ponto de equilíbrio nessas ações fomentadas, as quais devem visar a sustentação do planeta em consonância econômica, ambiental e social (ABRAMOVAY, 2010).

Os debates ocorridos em nível mundial, que passaram a ser propostos a partir de 1960, trouxeram questionamentos sobre o crescimento econômico, consumo e preservação dos recursos, colocando em xeque o estilo de vida das nações consideradas desenvolvidas, tentando compilar dados que demonstrassem essa insegurança do planeta e da perspectiva de manutenção da vida (ABRAMOVAY, 2010).

Muito se tem falado sobre desenvolvimento sustentável, sustentabilidade e outros termos atrelados a esse sentido. O termo sustentável ganhou destaque e passou a interessar a comunidade científica, a partir da década de 1980 (KAMIYAMA, 2011).

O termo "desenvolvimento sustentável" tem suas origens a partir da conferência de Estocolmo, em 1972, que foi precedida no período por diversas reuniões pelo mundo. A comunidade científica aliada à Organizações Não - Governamentais (ONGs) passaram a discutir e promover ações em reuniões que resultaram em inúmeros trabalhos e relatórios dentre eles o Relatório de Founex, o qual discute a relação do meio ambiente $\mathrm{x}$ desenvolvimento, trazendo uma visão de união e equilíbrio entre esses, precavendo a sociedade sobre a necessidade de uma abordagem reducionista em aspectos do consumismo e de preservação do meio ambiente (SACHS, 1993).

Sachs (1993) aborda os princípios básicos dessa nova visão, a qual atrela a economia e o meio ambiente, uma abordagem que começa a cunhar de forma mais consistente e prática o desenvolvimento sustentável. Passa a debater e difundir o termo ecodesenvolvimento, que analisa a conexão do homem com a natureza, que fora introduzido por Maurice Strong em 1972 (MONTIBELLER-FILHO, 2008).

Na dialética do homem e da natureza, Marx traz uma visão de que apenas quando os homens se conectarem e se inserirem no nexo vivo da natureza, serão capazes de compreender a essência de sua existência e de suas tarefas como seres humanos. Os preceitos de solidariedade devem pautar a 
sociedade, promovendo uma conexão simultânea com a atividade produtiva consciente. Sendo a sociedade uma unidade essencial completada pelo homem e a natureza (SCHMIED-KOWARZIK, 2019).

A conexão homem e natureza dá a base na concepção de Fiorillo (2009) para o desenvolvimento sustentável, o qual estabelece um equilíbrio entre o desenvolvimento social, o crescimento econômico e a utilização dos recursos naturais. Desta forma, o princípio do desenvolvimento sustentável visa a manutenção das bases vitais da produção e reprodução do homem nos mais amplos aspectos de identidade e atividades, garantindo assim, uma relação satisfatória entre homem e a natureza (FIORILLO, 2009).

No contexto do pensamento ambiental, ao se discutir sobre sustentabilidade, Boff (2016) afirma que se deve dar uma atenção especial para a chamada "Pegada Ecológica da Terra", avaliando o quanto de solo, nutrientes, água, florestas e energia, tudo que o planeta precisa para alcançar a reparação dos danos causados pelo consumo humano.

A ideia de crescimento incessante de produção e consumo, numa corrida desenfreada por inovação tem perdurado há várias décadas. Entretanto, essa ideia se choca com os limites que os ecossistemas impõem ao aparato produtivo. Mais que isso, demonstra a discrepância entre a expansão da produção de bens e serviços e da obtenção real de bem-estar para as pessoas, comunidades e territórios (ABRAMOVAY, 2012).

Não se pode falar em desenvolvimento sustentável, sem entender a Sustentabilidade e a visão definida por Boff (2014). Todas as ações visam manter equilibrada a vida dos seres na Terra e reverberam a continuidade desse equilíbrio para a presente e futuras gerações, de forma a manter o capital natural, seja mantido e enriquecido em sua capacidade de regeneração, reprodução e coevolução.

Ainda nesse norte o autor descreve o modelo padrão de desenvolvimento sustentável, chamado de Triple Bottom Line, que deve garantir a sustentabilidade. Conforme Boff (2010), para que o desenvolvimento seja sustentável, ele deve ser economicamente viável, socialmente justo e ambientalmente correto. 
Mesmo havendo concepções e discordâncias sobre o conceito de Desenvolvimento Sustentável, o tripé econômico, social e ambiental é uma das teorias mais aceitas no meio científico (STOFFEL; COLOGNESE, 2015).

Para Sen (2000), que foi consultor para o Human Development Reports da Organização das Nações Unidas (ONU), o desenvolvimento pode ser concebido como um processo de expansão da liberdade.

O desenvolvimento com crescimento do Produto Nacional Bruto (PNB), aumenta as rendas das pessoas, promove a industrialização, avanços tecnológicos ou modernização social. Para além do desenvolvimento econômico, se faz necessário o desenvolvimento social, dando real atenção à saúde, educação e garantias individuais civis (SEN, 2000).

Assim, o desenvolvimento sustentável deve ser concebido como um pacto com as futuras gerações, deve trazer uma inquietação de todos: poder público, sociedade organizada e cidadãos, pois o caminho para o desenvolvimento sustentável deve ser impetrado e organizado, devendo ser implantado através de políticas públicas que visem estimular o consumo consciente e preservar os recursos naturais de forma a promover a eliminação da produção que destrói o meio ambiente (HOFFMANN, 2005).

\section{TECNOLOGIA E DESENVOLVIMENTO RURAL SUSTENTÁVEL}

Para fundamentar a relação humanidade/natureza com propostas de desenvolvimento socioeconômico há que se prever um caminho de transição para, em longo prazo, minimizar o esgotamento dos recursos não renováveis e reorientar o aproveitamento dos recursos renováveis.

O agravamento da degradação ambiental impulsionado pelo crescimento econômico passou a ser discutido com mais ênfase nas últimas décadas do século $\mathrm{XX}$ e abriu campo para as diferentes estratégias que abordam a gestão ambiental. Essa crise ambiental pouco a pouco tem feito que os grupos econômicos visualizem a necessidade de compreender a problemática do desenvolvimento sustentável, pois dessa forma poder-se-á garantir um desenvolvimento econômico, cujo produto terá uma utilização social justa, aliada a uma preocupação ecologicamente consciente e sustentável (SACHS, 1996; BOFF, 2003; LEFF, 2009).

Um dos vários segmentos colocados como possivelmente sustentável é o espaço rural, com destaque para a agricultura e pecuária. Em relação a esse tema se faz pertinente trazer algumas 
concepções e conceitos, visando discutir os problemas e as possibilidades relacionados ao desenvolvimento rural sustentável, antes de se apontar aspectos da inclusão da inovação e tecnologia como fomento a esse desenvolvimento no setor (LEFF, 2009).

No tocante ao desenvolvimento rural sustentável, se tem como marco a publicação do livro "Primavera Silenciosa" de Rachel Carson na década de 1960, que trouxe a discussão da consciência ambiental e dos impactos do setor agrário para o planeta, o que corroborou com a Conferência das Nações Unidas sobre o Meio Ambiente Humano realizada em Estocolmo em 1972, também conhecida como Carta de Estocolmo (SACHS, 2009).

Esse conjunto de estudos serviu de base naquele momento para vislumbrar, mesmo que superficialmente, os limites da racionalidade econômica e os desafios da degradação ambiental ao projeto civilizatório da modernidade, trazendo a sustentabilidade para o centro do debate em suas diversas ramificações, inclusive no meio rural (LEFF, 2009).

No contexto do desenvolvimento sustentável é importante priorizar a discussão de produção e consumo, pois a base econômica mundial tem esses pilares como princípios, buscando resultados econômicos crescentes, no entanto esses resultados levam ao esgotamento e à contaminação dos recursos naturais, criação de abismos sociais entre as nações, bem como dentro delas. O setor rural está integrado a economia e a sociedade, sendo de suma importância para o desenvolvimento local, do país e a nível mundial.

De acordo com Navarro (2001), o termo 'desenvolvimento rural' pode ser concebido como ações articuladas que visam induzir mudanças no ambiente rural. As ações propostas e executadas pelo Estado focaram no desenvolvimento rural, a fim de assegurar estabilidade ao setor através de mecanismos de mudança social.

Por desenvolvimento rural sustentável, se compreende a forma que se estabelece o modo produtivo, ao qual venha desenvolver os fatores que influenciam o modo de produção, desde a força de trabalho, gerando distribuição da renda, diminuindo as privações de liberdades individuais e sociais, fomentando a liberdade do camponês, de modo a equilibrar a cultura e características desses trabalhadores do campo com o desenvolvimento que promova o uso racional dos recursos naturais disponíveis para a produção agrícola (POULAIN, 2013). 
Wanderley (2009) expressa um conceito sobre o mundo rural como sendo um universo integrado à sociedade brasileira e ao contexto internacional. Retirando a visão de que atualmente o meio rural é isolado, ao contrário, traz a concepção de que o funcionamento do meio social depende do meio rural para o equilíbrio de seu funcionamento.

Ao considerar que o desenvolvimento rural pode ser socialmente includente, Sachs (2009) frisa que somente o acesso à terra não leva a um desenvolvimento rural sustentável. Aliando o acesso a tecnologias, educação, políticas públicas e a consolidação do processo de industrialização de forma sustentável, é possível levar o sucesso ao âmbito rural e, consequentemente, a um desenvolvimento sustentável que entregue como resultados o crescimento econômico, a preservação ambiental e a equidade social.

O processo de modernização da agricultura ocorrido no país se deu de forma excludente e teve como fator agravante a expansão das fronteiras agrícolas do Brasil. Esse processo ocasionou muitos impactos econômicos, sociais e ambientais, pois a modernização se baseou nos anseios mercadológicos de consumo, não se preocupando com a manutenção dos recursos naturais, tendo um uso intensivo de pacotes tecnológicos, mecanização de trabalho, na seleção das espécies, na monocultura, no latifúndio e no consumismo descontrolado (ZAMBERLAN; FRONCHETI, 2001).

O processo de modernização da agricultura brasileira teve seu fomento através de políticas públicas para a área rural, entretanto, inicialmente essas ações privilegiaram os setores mais capitalizados e a esfera produtiva das commodities voltadas ao mercado internacional, deixando de fora os pequenos produtores de agricultura familiar, o que promoveu uma grande discrepância e desequilíbrio para o setor da produção familiar, tendo resultado altamente negativo, pois a falta de investimentos nesse segmento deixou o pequeno produtor atrasado em relação às tecnologias empregadas no campo para promover um desenvolvimento rural consistente (MATTEI, 2007).

Ainda sobre os pequenos produtores, Plein (2016) expressa que a relação de mercado dos agricultores familiares com os consumidores que absorvem a produção, traduz um universo inverso de desenvolvimento, pela histórica falta de investimentos que promove um excesso de trabalho e pouco desenvolvimento, que vagarosamente tem mudado com a utilização de tecnologias e da ciência, que visam facilitar o manejo na agricultura tornando-a menos penosa, promovendo o desenvolvimento rural sustentável no qual se fomenta uma melhor distribuição de renda. 
A aplicação de ciência e tecnologia na agricultura familiar promoveu a melhoria no funcionamento desse setor, tendo impacto direto no agricultor familiar, trazendo mais liberdade ao homem do campo e o conectando as orientações do mercado. Algo que se fundamentou como premissa de desenvolvimento rural sustentável em todos os segmentos do rural, seja nas grandes propriedades, commodities ou na agricultura familiar é a aplicação de ciência e tecnologia como estratégias para o desenvolvimento sustentável (SACHS, 2009).

Os avanços tecnológicos promovidos auxiliaram na globalização do mundo rural brasileiro, esse grande poder tecnológico que promove intensas transformações no modo de produção e de consumo com base em um desenvolvimento rural sustentável, que busca aliar as liberdades econômicas de mercado sem deixar de lado os pilares sociais e ambientais. Esses avanços tecnológicos estão conectando o meio rural à globalização de mercado, provocando impactos econômicos e sociais que resultam em subdesenvolvimento (SACHS, 2001; SEN, 2000).

Muitas propostas para um novo padrão produtivo para o meio rural foram criadas nas últimas décadas, entretanto a maioria dessas propostas foram vistas como dispendiosas para os métodos produtivos, como também para recuperação de áreas já degradadas; essas propostas fizeram com que os setores rurais entrassem em crise com os movimentos ambientalistas (ALTIERI; MASERA, 1997).

O desenvolvimento rural possui diversas faces e atores, e deve ser pensado de forma a ser direcionado a um desenvolvimento sustentável e promovido pelo Estado com políticas públicas sólidas a fim de repensar o meio rural. As políticas públicas que visam atuar em prol da sustentabilidade devem sempre equilibrar entre os pilares que a constituem: o ambiental, o social e o econômico. Essa harmonização dos objetivos visa trazer o bem-estar no presente e no futuro, tratando-se de um princípio constitucional que, independentemente de regulação legal, possui eficácia direta e imediata (ALMEIDA, 2017).

Afinal, compreender a importância dos recursos naturais, e o manejo sustentável, combinando a pesquisa cientifica, inovação e tecnologia, de forma a promover a manutenção dos recursos naturais, o aumento da produtividade e da renda. Esse processo de desenvolvimento rural sustentável pode parecer utópico, entretanto é almejado pelo segmento rural e pela sociedade atual, que necessita de um desenvolvimento realmente aliado a sustentabilidade (SACHS, 2009). 


\section{TECNOLOGIA FOTOVOLTAICA PARA O FOMENTO DO DESENVOLVIMENTO RURAL SUSTENTÁVEL}

Atualmente, a agricultura é um dos principais pilares econômicos dos países e possui pontos de benefícios, principalmente na geração de empregos no setor de serviços a ela conectada. Em contrapartida, o contexto de desenvolvimento rural é considerado um dos grandes vilões da crise ambiental e a biodiversidade, tanto pela emissão de gases do efeito estufa, quanto ao desmatamento, que promove a degradação das florestas mundiais para o avanço das áreas agricultáveis (AZNARSÁNCHEZ et al., 2019).

Conforme Liu, Zhang e Bae (2017), o setor rural atualmente é considerado o segundo maior emissor de gases de efeito estufa, chegando a ser responsável por $21 \%$ do total mundial das emissões. Entretanto, a atividade agrícola possui elementos que podem contribuir com a redução desses gases estufa de forma significativa quando utilizam produtos e subprodutos de forma sustentável, como na produção de energias renováveis por meio de biogás, biocombustíveis e biomassa, que além de reduzirem os custos da atividade.

Além da utilização de produtos e subprodutos na produção de energia, o uso da energia solar fotovoltaica na agricultura tem se expandido, além de ser uma fonte natural de luz e calor, essencial para manutenção da vida na Terra, e considerado uma fonte inesgotável e renovável, e uma tecnologia com grande viabilidade econômica (TOLMASQUIM, 2016).

Os gastos com energia na agricultura em seus vários segmentos representam uma expressiva despesa, muitas vezes figurando como um dos maiores custos indiretos. Como solução a esses custos financeiros, muitos países têm fomentado a utilização de energia solar fotovoltaica, promovendo políticas públicas de fomento à utilização da tecnologia nos vários segmentos agrários (HASSANIEN; LI; LIN, 2016).

Apesar de ainda os sistemas solares apresentarem um custo inicial relativamente alto, com os fomentos advindos das políticas públicas, esses sistemas passaram a ter maior viabilidade econômica, que se juntam aos pilares ambientais e sociais dessa fonte sustentável e limpa (HASSANIEN; LI; LIN, 2016).

As aplicações de sistemas geradores fotovoltaicos na área rural segundo Mesquita (2014) e Camargo e Ribeiro (2010) configuram uma solução promissora para a eletrificação rural. Entretanto 
cada país detém especificações que podem aumentar ou diminuir os benefícios da aplicação da tecnologia. No caso do Brasil, que é um país com proporções continentais, se deve compreender a aplicação da tecnologia fotovoltaica adaptada às especificidades locais e regionais.

Mesquita (2014) reforça que diversas tentativas de eletrificação rural foram implantadas pelo mundo, porém muitas destas levaram em conta apenas as especificações técnicas, o que fizeram não atingir os objetivos de sustentabilidade esperados pelo setor elétrico.

Vários são os segmentos rurais que podem ser atendidos pela implementação de sistemas fotovoltaicos. De acordo com Snegirjovs et al. (2018), a utilização de energia solar é viável economicamente na exploração leiteira em maquinário de resfriamento e ordenha mecanizada, em que o consumo de energia é elevado.

Ainda no segmento leiteiro o pesquisador Wells (2001), analisou a implementação de 150 fazendas produtoras de leite na Nova Zelândia, onde identificou que a implantação da tecnologia fotovoltaica se mostrou benéfica e viável, reduzindo os custos de energia elétrica no segmento, além de os pesquisados perceberem que a tecnologia fomenta positivamente na saudabilidade do ambiente.

Para Camargo e Ribeiro (2010), o sistema fotovoltaico mostra-se importante e capaz de instituir o sentimento de inclusão na área urbana e rural. $\mathrm{O}$ autor destaca que o processo de eletrificação rural por meio deste sistema é uma atitude que propõe inovações que necessitam ser aplicadas e socializadas. E que a tecnologia é promissora para diversas áreas do setor agrário, onde as pesquisas vêm demonstrando viabilidade e sustentabilidade em empreendimentos como granjas, pecuária de leite, piscicultura, agroindústrias, agricultura familiar, entre outras atividades rurais. Apesar dos custos elevados a sua disseminação deve ser fomentada através de políticas públicas e incluída nos planos de modernização e infraestruturas do meio rural.

Usar a tecnologia de energia solar oferece meios de lidar com a pobreza e subdesenvolvimento no meio rural, tendo uma relação positiva que visa promover o desenvolvimento rural sustentável. Portanto, a promoção do desenvolvimento rural sustentável através da aplicação da tecnologia pode ser observada por meio de alguns indicadores que vão além dos financeiros e econômicos, mas buscam levantar dados ambientais e sociais da aplicação da tecnologia fotovoltaica no setor agrário (SHAFIEISABET; MIRVAHEDI; HARATIFARD, 2020). 
Assim como em muitas partes do mundo, desde a autorização da utilização de sistemas geradores fotovoltaicos conectados à rede no Brasil pela Resolução normativa ${ }^{\circ} 482$ de 2012, está sendo observada uma ascensão da utilização da tecnologia tanto na área urbana quanto na área rural. No Estado do Paraná esse fenômeno também vem ocorrendo, mesmo se tendo um alto potencial hídrico de geração, o Estado possui viabilidade técnica para geração de energia por fonte fotovoltaica e gradativamente o setor rural paranaense vem investindo no segmento de energia solar fotovoltaica (ANEEL, 2012).

\section{PANORAMA E ASCENSÃo da GERAÇÃo Distribuída POR FONTE SOLAR FOTOVOLTAICA NA ZONA RURAL DA REGIÃO ADMINISTRATIVA DE UMUARAMA}

O Estado do Paraná situa-se ao sul do Brasil, com área de 199.880 km2, com uma população de 10.444.526 habitantes, distribuída em 399 municípios, e que apresentou no ano de 2020 um consumo de energia elétrica de aproximadamente 29 TWh (IPARDES, 2020).

Segundo Tiepolo et al. (2014), o potencial hidráulico do Estado do Paraná é superior a 24 GW, se tendo explorado grande parte dos recursos disponíveis para produção de energia por essa fonte geradora. Nesse rumo, devido a pressões da sociedade, visando minimizar os impactos ambientais, o Estado vem buscando fomentar a diversificação da matriz elétrica, procurando investir em energias renováveis, como eólica e solar.

De modo a realizar uma comparação, o potencial solar no Paraná é cerca de $43 \%$ mais viável que na Alemanha, um dos países europeus com maiores investimentos em energia solar fotovoltaica no mundo. Nesse mesmo aspecto, ao analisar a viabilidade em relação ao Reino Unido que é um dos líderes na utilização de sistemas geradores por fonte fotovoltaica no mundo, do qual segundo o Atlas Brasileiro de Energia Solar confirma que, o potencial solar do Paraná em relação a este país é 55\% maior. Essas afirmações podem ser observadas na Figura 2 que demonstra através de escala de valores e cores a irradiação solar total média anual (PEREIRA, 2017).

A viabilidade técnica da aplicação de energia solar fotovoltaica vem sendo demonstrada em pesquisas científicas do segmento, onde se faz um comparativo entre o estado paranaense e os seus índices de irradiação solar e produtividade total anual média de $1.986 \mathrm{kWh} / \mathrm{m}^{2}$ em comparação aos países europeus, com valores de irradiação e produtividade total anual média de $1.490 \mathrm{kWh} / \mathrm{m}^{2}$ (TIEPOLO et al., 2014). 


\section{GESTÃO \& SUSTENTABILIDADE AMBIENTAL}

\section{¿unisul sim}

Figura 2. Comparação do potencial fotovoltaico encontrado no estado do Paraná com a Europa.

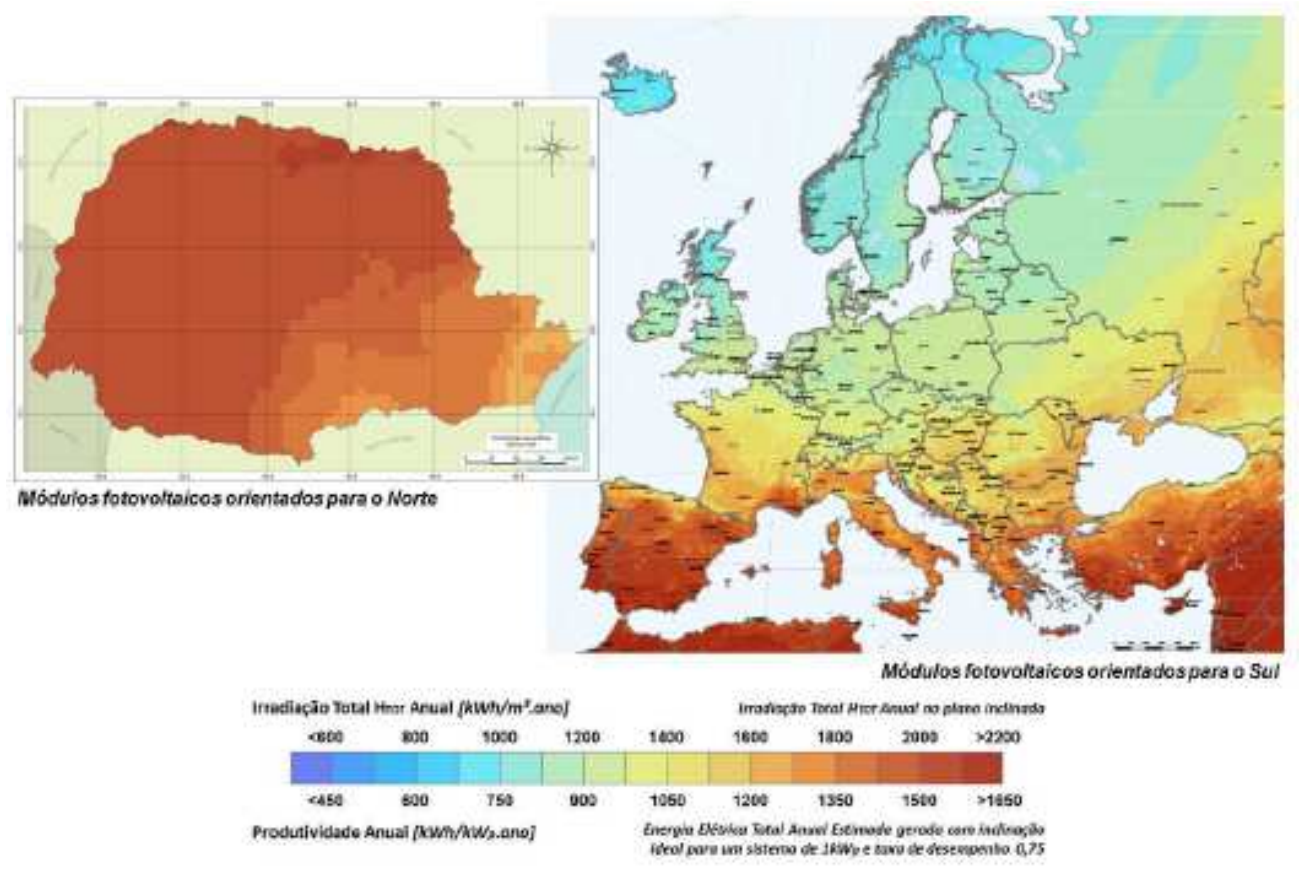

Fonte: TIEPOLO et al. (2014).

Atualmente, o Estado do Paraná se consolidou, segundo a Associação Brasileira de Energia Solar Fotovoltaica (ABSOLAR), como o $5^{\circ}$ estado brasileiro no ranking de geração distribuída, conforme a Figura 3, tendo 285,3 MW de potência instalada, cerca de 5,6\% do total da energia produzida no país na modalidade de geração distribuída por fonte solar fotovoltaica. Entretanto, deve ser levado em consideração que a adesão da modalidade residencial é o maior potencial instalado no estado, que representa 39,2\%, seguido de comércios e serviços, que corresponde a 37,8\% (ABSOLAR, 2021).

A tecnologia fotovoltaica na área rural, apesar de ter progresso menor comparado a outros estados, demonstrou avanços impulsionados principalmente pela extrafiscalidade e políticas públicas. A geração distribuída por fonte fotovoltaica na área rural do Brasil alcançou em setembro de 2021 a marca de 839.203 kW instalados. Já na área rural da região sul do país há 238.660 kW instalado desse montante, divididos em 123.490 kW no Rio Grande do Sul, 66.808 kW em Santa Catarina e 48.360,93 kW no Paraná (ANEEL, 2021). 


\section{১unisul sim}

Figura 3. Ranking estadual de geração distribuída por potência instalada.

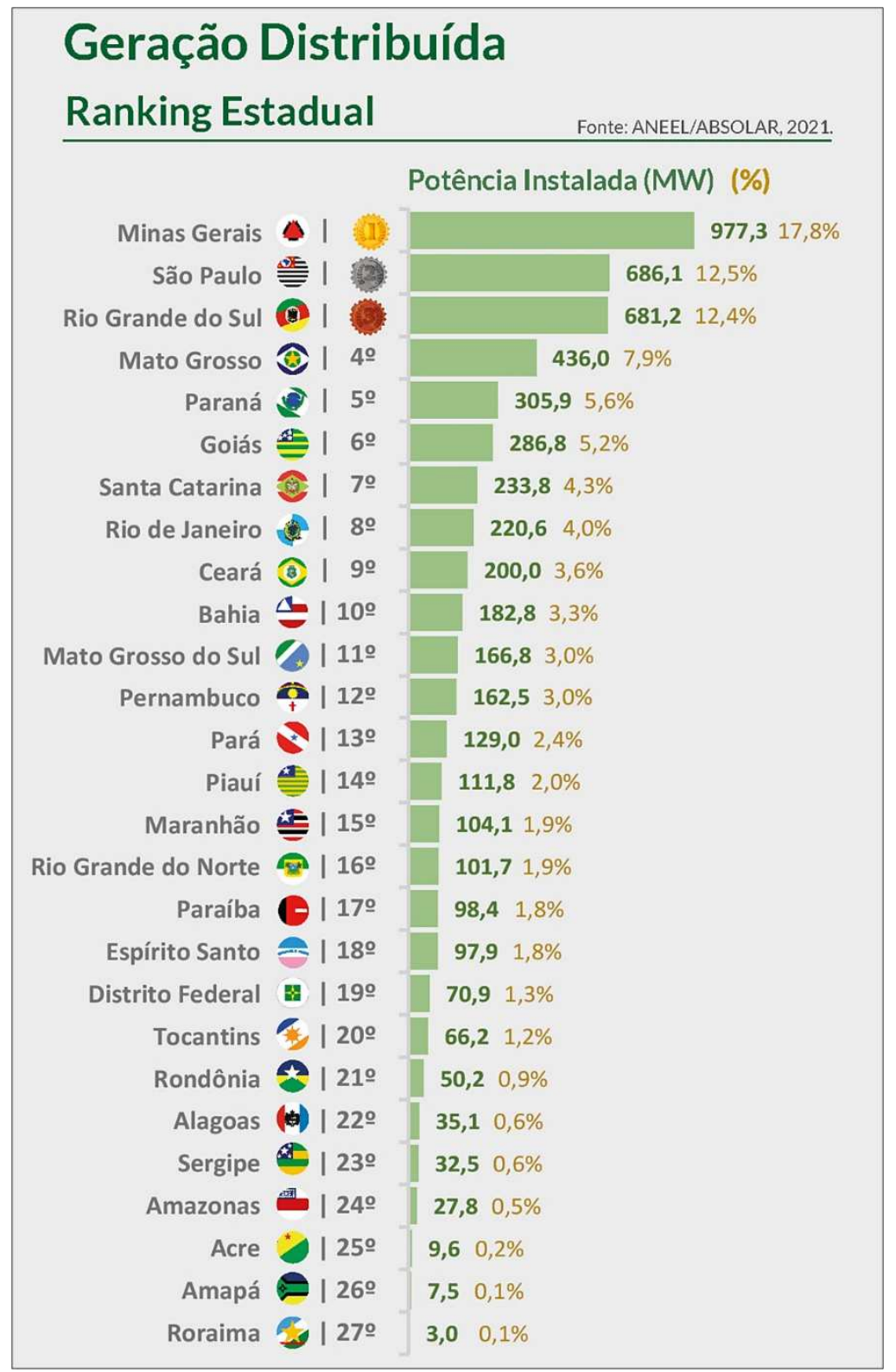

Fonte: ABSOLAR (2021).

Para o recorte da pesquisa, foram levadas em consideração as conexões efetivadas em geração distribuída por fonte solar fotovoltaica da Região Administrativa de Umuarama no Estado do Paraná, conforme observado no Tabela 1. Esta região detém cerca de 4,56\% do potencial de produção de energia em geração distribuída fotovoltaica na área rural do Estado do Paraná. Além disso, os municípios de Cianorte, Iporã e Francisco Alves são os líderes em potência instalada na área rural desta região (ANEEL, 2021). 
Tabela 1: Conexões e potência instalada de sistemas fotovoltaicos em geração distribuída na área rural da região administrativa de Umuarama - PR até 09/2021.

\begin{tabular}{lrr}
\hline MUNICÍPIO & UNIDADES & POTÊNCIA $(\mathbf{K W})$ \\
\hline ALTO PARAÍSO & 0 & 0,00 \\
ALTO PIQUIRI & 2 & 80,40 \\
ALTÔNIA & 17 & 306,06 \\
BRASILÂNDIA DO SUL & 10,00 \\
CAFEZAL DO SUL & 2 & 78,00 \\
CRUZEIRO DO OESTE & 4 & 7,50 \\
DOURADINA & 1 & 77,82 \\
ESPERANÇA NOVA & 4 & 230,84 \\
FRANCISCO ALVES & 8 & 322,30 \\
ICARAIMA & 10 & 24,00 \\
IPORÃ & 2 & 592,70 \\
IVATÉ & 10 & 1,50 \\
MARIA HELENA & 1 & 24,20 \\
MARILUZ & 3 & 30,00 \\
NOVA OLIMPIA & 1 & 60,00 \\
PEROBAL & 1 & 91,10 \\
PÉROLA & 9 & 80,50 \\
SÃO JORGE DO PATROCÍNIO & 3 & 141,85 \\
TAPIRA & 6 & 6,00 \\
UMUARAMA & 1 & 396,81 \\
XAMBRE & 21 & 5,00 \\
\hline TOTAL & 1 & $2.566,58$ \\
\hline & 107 &
\end{tabular}

Fonte: ANEEL (2021).

Os dados levantados, informados pelas companhias de energia para a Agência de Energia Elétrica (ANEEL), corroboram com a perspectiva do Plano Decenal de Expansão de Energia 2030, e seguem os mesmos parâmetros que já vem acontecendo na área rural, dos quais muitos países vem incentivando a eletrificação rural implementada por fonte solar fotovoltaica (EPE, 2021).

O Estado do Paraná, motivado pela necessidade de segurança energética e objetivando torna sua matriz elétrica mais sustentável em consonância com o objetivo 7 dos Objetivos de Desenvolvimento Sustentável (ODS) propostos pela ONU, lançou no segundo semestre de 2021 o primeiro programa de fomento à eletrificação rural por fontes renováveis, nomeado de Programa Paraná Energia Rural Renovável (RENOVAPR) (PARANÁ, 2021). 
O programa visa estimular a produção interna e própria de energia nas unidades produtivas, reduzir o custo da produção rural, trazer competitividade dos produtos agrícolas e agropecuários, fomentar as economias locais, gerar trabalho e renda, entre outros fatores que visam promover um desenvolvimento rural sustentável através da aplicação da tecnologia, pautada na extrafiscalidade, onde o Governo Estadual vai subsidiar os juros do financiamento para aquisição desses sistemas. A primeira fase do programa irá beneficiar os agricultores rurais que participam do programa paranaense Tarifa Rural Noturna, posteriormente se pretende ampliar para todos os outros segmentos rurais e agroindustriais (IDR-PARANÁ, 2021).

Com a efetivação do programa estadual para fomento a energias renováveis as perspectivas são favoráveis à ascensão da tecnologia fotovoltaica na área rural do Estado do Paraná, e se espera uma grande adesão pela região administrativa de Umuarama, que atualmente está cadastrando empresas integradoras para instalação da tecnologia através do programa estadual, que será efetivado pela parceria com o Banco do Brasil e a cooperativa financeira Sicredi, que estão promovendo linhas próprias de financiamentos ao setor fotovoltaico (CIDADE PORTAL, 2021).

\section{CONSIDERAÇÕES FINAIS}

A energia solar é uma das alternativas energéticas mais promissoras para o futuro e muito importante na preservação do meio ambiente. A crescente preocupação com as questões ambientais tem estimulado o desenvolvimento de novas fontes de energia limpa e renovável.

Essa preocupação em se utilizar fontes mais renováveis é reflexo da evolução das premissas de desenvolvimento sustentável o que deve ser concebido como um pacto com as futuras gerações, deve trazer uma inquietação de todos: poder público, sociedade organizada e cidadãos.

No tocante ao segmento rural, se busca integrar o desenvolvimento sustentável, afinal a agricultura possui pontos de benefícios como a geração de empregos, fomento à economia e aos setores de serviços, contudo também é considerada uma vilã da crise ambiental e a biodiversidade, tendo sido buscado através dos estudos de desenvolvimento rural sustentável, se compreender a forma que se estabelece o modo produtivo no campo.

O desenvolvimento rural sustentável visa demonstrar a importância do manejo sustentável, da responsabilidade com os recursos naturais, combinando a pesquisa cientifica, inovação e tecnologia 
no fomento ao setor, sendo a aplicação de novas tecnologias um dos grandes aliados nessa promoção do desenvolvimento rural sustentável.

A aplicação da tecnologia fotovoltaica no setor de agronegócio está despontando, pois o investimento em novas tecnologias promove a inovação da produção e aumenta a competitividade, impulsionada pelo fator redução econômica, pois os gastos com energia na agricultura em seus vários segmentos representam uma expressiva despesa, muitas vezes figurando como um dos maiores custos indiretos.

A viabilidade técnica da aplicação de energia solar fotovoltaica no Estado do Paraná se demonstrou eficaz e propícia a instalações de sistemas fotovoltaicos, sendo a irradiação, clima entre outros fatores favoráveis a utilização. Esses fatores elevaram a aplicação da tecnologia no Estado, que atualmente ocupa a $5^{\text {a }}$ colocação no ranking de utilização dos sistemas geradores fotovoltaicos, contudo o segmento rural ainda está tímido na utilização da tecnologia.

Deste modo, conclui-se que a energia solar fotovoltaica tem promovido o desenvolvimento rural sustentável, aliando a utilização de inovação, tecnologia em prol da sustentabilidade. No tocante à utilização da energia solar no Estado do Paraná e na Região Administrativa de Umuarama, os fatores ambientais são considerados propícios e favoráveis a implementação desses sistemas geradores fotovoltaicos, tendo viabilidade econômica, social e ambiental dessa integração em geração distribuída.

\section{REFERÊNCIAS}

\section{ABRAMOVAY, R. Desenvolvimento sustentável: qual a estratégia para o Brasil. Novos Estudos, CEBRAP, N 87, pp.1-11, 2010.}

ABSOLAR. Panorama da solar fotovoltaica no Brasil e no mundo. São Paulo, 2021. Disponível em: https://www.absolar.org.br/mercado/infografico/. Acesso em: 22 out. 2021.

\section{ALMEIDA, W. C. Direito, desenvolvimento e meio ambiente: teoria e prática. Curitiba: CRV,} 2017.

ALTIERI, M., MASERA, O. Desenvolvimento rural sustentável na América Latina: construindo de baixo para cima. In: ALMEIDA, J., NAVARRO, Z. (Eds.). Reconstruindo a agricultura: ideias e ideais na perspectiva desenvolvimento sustentável. Porto Alegre: UFRGS, 1997. p. 72-105.

ANEEL. Resolução Normativa no 482, de 17 de abril de 2012. Brasília: Diário Oficial da União, 2012. Disponível em: http://www2.aneel.gov.br/cedoc/ren2012482.pdf. Acesso em: 21 out. 2021.

ANEEL. Outorgas e Registros de Geração: Unidades consumidoras com geração distribuída. SCG, 2021. Disponível em: http://www.aneel.gov.br/outorgas/geracao/-/asset_publisher/mJhnKIi7 
qcJG/content/registro-de-central-geradora-de-capacidade-reduzida/655808. Acesso em: 21 out. 2021.

AZNAR-SÁNCHEZ, J. A.; BELMONTE-UREÑA, L. J.; VELASCO-MUÑOZ, J. F.; VALERA, D. L. Aquifer Sustainability and the Use of Desalinated Seawater for Greenhouse Irrigation in the Campo de Níjar, Southeast Spain. International Journal of Environmental Research and Public Health, v. 16, n. 5, p. 898, 2019. DOI: https://doi.org/10.3390/ijerph16050898.

BOFF, L. Cuidar da Terra, proteger a vida: como evitar o fim do mundo. 1. ed. Rio de Janeiro: Record, 2010.

BOFF, L. Ética e moral: a busca dos fundamentos. Petrópolis, RJ: Vozes, 2003.

BOFF, L. Saber Cuidar: Ética do humano - compaixão pela Terra. 20. ed. Rio de Janeiro: Vozes, 2014.

BOFF, L. Sustentabilidade: O que é - O que não é. 5. ed. Rio de Janeiro: Vozes, 2016.

CAMARGO, E. J. S.; RIBEIRO, F. S. Programa Luz para Todos: avanços e retrocessos - um novo estoque de excluídos. São Paulo: $10^{\circ}$ Congresso sobre Geração Distribuída e Energia no Meio Rural, 2015.

CAPORAL, F. R.; COSTABEBER, J. A. Agroecologia e desenvolvimento rural sustentável: perspectivas para uma nova Extensão Rural. Agroecologia e Desenvolvimento Rural Sustentável, v. 1, n. 1, p. 16-37, 2000.

CIDADE PORTAL. Estado cadastra empresas e responsáveis técnicos para programa de energia solar rural. Umuarama, PR, 2021. Disponível em: https://umuarama.cidadeportal.com.br/ $\mathrm{m} /$ noticia/112442/16-07-21/estado-cadastra-empresas-e-responsaveis-tecnicos-para-programa-deenergia-solar-rural. Acesso em: 20 out. 2021.

EPE. Matriz Energética e Elétrica. Ministério de Minas e Energia. Brasília: MME/EPE, 2021.

Disponível em: https://www.epe.gov.br/pt/abcdenergia/matriz-energetica-e-eletrica. Acesso em: 20 out. 2021.

FIORILLO, C.A.P. Curso de Direito Ambiental Brasileiro. 10. ed. São Paulo: Saraiva, 2009.

HASSANIEN, R. H. E; LI, M.; LIN, W. D. Advanced applications of solar energy in agricultural greenhouses. Renewable and Sustainable Energy Reviews, Amsterdã, v. 54, p. 989-1001, 2016. DOI: https://doi.org/10.1016/j.rser.2015.10.095.

HOFFMANN, J. M. L. Avaliação: mito e desafio: uma perspectiva construtivista. 35. ed. Porto Alegre: Mediação, 2005.

IDR-Paraná [Instituto de Desenvolvimento Rural do Paraná]. Chamada Pública Energia Solar. Curitiba: IAPAR-EMATER, 2021. Disponível em: http://www.idrparana.pr.gov.br/Pagina/ Chamada-Publica-Energia-Solar. Acesso em: 20 out. 2021.

IPARDES. Estado do Paraná - Região Administrativa. Curitiba, 2015. Disponível em: http://www.ipardes.pr.gov.br/sites/ipardes/arquivos_restritos/files/documento/2019-09/Regi\%C3 \%B5es\%20Administrativas\%20-\%20Paran\%C3\%A1.pdf. Acesso em: 20 out. 2021.

KAMIYAMA, A. Agricultura sustentável. São Paulo: Governo do Estado de São Paulo, Secretaria do Meio Ambiente, Coordenadoria de Biodiversidade e Recursos Naturais, 2011. 
KEMERICH, P. D. C.; FLORES, C. E. B.; BORBA, W. F.; SILVEIRA, R. B. Paradigmas da energia solar no Brasil e no mundo. Revista Eletrônica em Gestão, Educação e Tecnologia Ambiental, v. 20, n. 1, 2016. DOI: https://doi.org/10.5902/2236117016132.

LEFF, E. Ecologia, capital e cultura: a territorialização da racionalidade ambiental. Rio de janeiro, Editora Vozes, 2009.

LIU, X.; ZHANG, S.; BAE, J. The impact of renewable energy and agriculture on carbon dioxide emissions: Investigating the environmental Kuznets curve in four selected ASEAN countries. Journal of Cleaner Production, p. 164, 2017. DOI: https://doi.org/10.1016/j.jclepro.2017.07.086.

MATTEI, L. Políticas de Apoio ao Desenvolvimento da Agricultura Familiar no Brasil: O Caso Recente do Pronaf. Revista Econômica do Nordeste, Fortaleza, v. 38, n. 1, 2007.

MESQUITA, J. M. Método de Avaliação do Nível de Sustentabilidade de Programas de Eletrificação Rural com Sistemas Fotovoltaicos Individuais. Dissertação de Mestrado. Programa de Pós-Graduação em Engenharia Elétrica, Universidade Tecnológica Federal do Paraná. Pato Branco: UTFPR, 2014.

MONTIBELLER FILHO, G. O Mito do Desenvolvimento Sustentável. Florianópolis: UFSC, 2008.

NAVARRO, Z. Desenvolvimento rural no Brasil: os limites do passado e os caminhos do futuro. Estudos Avançados, São Paulo, v. 15, n. 43, p. 83-100, 2001.

NUNES, P. C. R. Energia solar: uma alternativa viável? Monografia, Departamento de Engenharia, Universidade Federal de Lavras. Lavras, MG: UFLA, 2007.

PARANÁ. Agência de Notícias do Paraná. Programa de apoio à energia sustentável, RenovaPR é apresentado ao setor agropecuário. Curitiba, 2021. Disponível em:

https://www.aen.pr.gov.br/modules/noticias/article.php?storyid=114043. Acesso em:19 out. 2021.

PEREIRA, E. B.; MARTINS, F. R.; GONÇALVES, A. R.; COSTA, R. S.; LIMA, F. L.; RÜTHER, R.; ABREU, S. L.; TIEPOLO, G. M.; PEREIRA, S. V.; SOUZA, J. G. Atlas brasileiro de energia solar. 2. ed. São José dos Campos: INPE, 2017.

POULAIN, J. P. Sociologias da alimentação: os comedores e o espaço social alimentar. 2. ed. Ed. Florianópolis: UFSC, 2013.

PLEIN, C. Desenvolvimento, mercados e agricultura familiar: uma abordagem institucional da pobreza rural. 1. ed. Curitiba, PR: CRV, 2016.

SACHS, I. (ed.). Quelles villes, pour quel développement? Paris: Presses Universitaires de France, 1996.

SACHS, I. Desenvolvimento e cultura. Caminhos para o desenvolvimento sustentável. Rio de Janeiro: Garamond, 2009.

SACHS, I. Repensando o Crescimento Econômico e o Progresso Social: o âmbito da política. In: ARBIX, G.; ZILBOVICIUS, M.; ABRAMOVAY, R. Razões e ficções do desenvolvimento. São Paulo: UNESP/EDUSP, 2001.

SCHMIED-KOWARZIK, W. A relação dialética do homem com a natureza: Estudos históricofilosóficos sobre o problema da natureza em Karl Marx. Cascavel, PR: EDUNIOESTE, 2019. 
SEN, A. Desenvolvimento como Liberdade. São Paulo: Companhia das Letras, 2000.

SHAFIEISABET, N.; MIRVAHEDI, N.; HARATIFARD, S. Social Capacities to Facilitate the Establishment of Solar Energy Technology and its Effects on Sustainable Rural Development (Case Study: Kerman Desert Region, Iran). Journal of Research and Rural Planning, v. 9, n. 3, 2020. DOI: https://doi.org/10.22067/jrrp.v9i3.86523.

SILVA, J. G. O novo rural brasileiro. Nova Economia, Belo Horizonte, v. 7, n. 1, p. 43-81, 1997. SNEGIRJOVS, A.; LEBEDEVA, K.; KASHKAROVA, G.; SHIPKOVS, P. Solar technologies application in milk production. 17TH International Scientific Conference Engineering for Rural Development, 2018. DOI: https://doi.org/10.22616/ERDev2018.17.N097.

STOFFEL, J. A.; COLOGNESE, S. A., 2000. A sustentabilidade na agricultura familiar: indicadores e índices econômicos e sociais de avaliação. Tempo da Ciência, v. 22, n. 44, p. 47-59. DOI: https://doi.org/10.48075/rtc.v22i44.12931.

TIEPOLO, G.; CANCIGLIERI, O.; URBANETZ, J.; VIANA, T.; PEREIRA, E. B. Comparação entre o potencial de geração fotovoltaica no estado do Paraná com Alemanha, Itália e Espanha. Recife: V Congresso Brasileiro de Energia Solar - V CBENS, 2014.

TOLMASQUIM, M.T. (ed.). Energia Renovável: Hidráulica, Biomassa, Eólica, Solar, Oceânica. Rio de Janeiro: EPE, 2016.

WANDERLEY, M. N. B. O mundo rural como espaço de vida: reflexões sobre a propriedade da terra, agricultura familiar e ruralidade. Porto Alegre: Ed. UFRGS, 2009.

WELLS, C. M. Total energy indicators of agricultural sustainability: Dairy farming case study final report. Report to MAF Policy, Dept. of Physics, University of Otago, 2001.

ZAMBERLAN, J.; FRONCHETI, A. Preservação do pequeno agricultor e o meio ambiente.

Petrópolis: Vozes, 2001 